\title{
On the reaction of indole-3-carbaldehyde with cyanothioacetamide: an unexpected approach to indolyl-substituted pyridines and thieno[2,3- b]pyridines
}

\author{
Victor V. Dotsenko ${ }^{1,2 *}$ and Sergey G. Krivokolysko ${ }^{2,3}$ \\ ${ }^{1}$ Kuban State University, 149 Stavropolskaya str, Krasnodar, 350040 Russia \\ e-mail: victor_dotsenko@bigmir.net \\ ${ }^{2}$ ChemEx Lab, Vladimir Dal' Lugansk National University, 20A/7 Molodezhny, \\ Lugansk, 91034 Russia \\ ${ }^{3}$ Lugansk State Medical University, 1-g 50 years of Lugansk Defence, Lugansk \\ 91045, Russia
}

\section{Abstract}

The reaction of cyanothioacetamide with indole-3-carbaldehyde in the presence of $\mathrm{KOH}$ surprisingly leads to potassium 6-amino-3,5-dicyano-4- $(1 \mathrm{H}$ indol-3-yl)pyridine-2-thiolate in good yield. The mechanism is discussed. Upon treatment with alkylating agents, the thiolate gave new 2(alkylthio)pyridines and thienopyridines bearing 3-indolyl moiety.

\section{Keywords}

cyanothioacetamide, indole-3-carbaldehyde, Michael reaction, Thorpe-Ziegler cyclization, thienopyridines

The reaction of active methylene (thio)amides with $\beta$-enamino carbonyls have been recognized as a convenient approach to various $\mathrm{N}$-heterocyclic systems. At the outset of our studies we have been focused on the reaction of cyanothioacetamide 1 with indole-3-carbaldehyde $\mathbf{2}$ that we supposed to be the method for the synthesis of 5-(2-aminophenyl)pyridine-2-thiolates 3 . In this context, indole-3-carbaldehyde 2 could be considered as cyclic $\beta$-enamino aldehyde, and the product of Knoevenagel condensation with thioamide 1, 3(1H-indol-3-yl)-2-cyanoprop-2-enethioamide 4 could be represented as indole bearing at $\mathrm{C}-3$ position a nucleophilic group which can attack $\mathrm{C}-2$ position to cleave pyrrole ring, as shown in Scheme 1. 


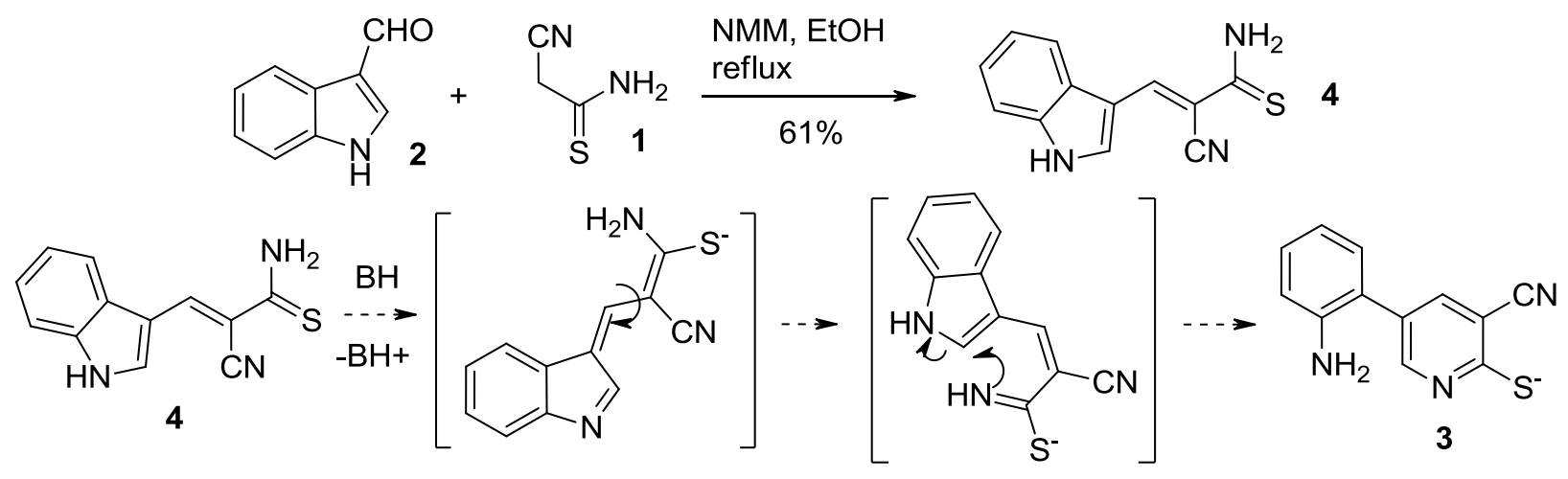

A brief survey of literature revealed that such a cleavage of indole system upon the action of $\mathrm{N}$-nucleophiles is known and have been reported before [17]. It have been noted $[5,7]$ that an electron-withdrawing group at $\mathrm{C}-3$ favors the cleavage, and indoles bearing $\mathrm{CHO}$ or acyl group at $\mathrm{C}-3$ position can react as 1,3-CCC-dielectrophiles with (di)nucleophiles to give a variety of recyclization products:

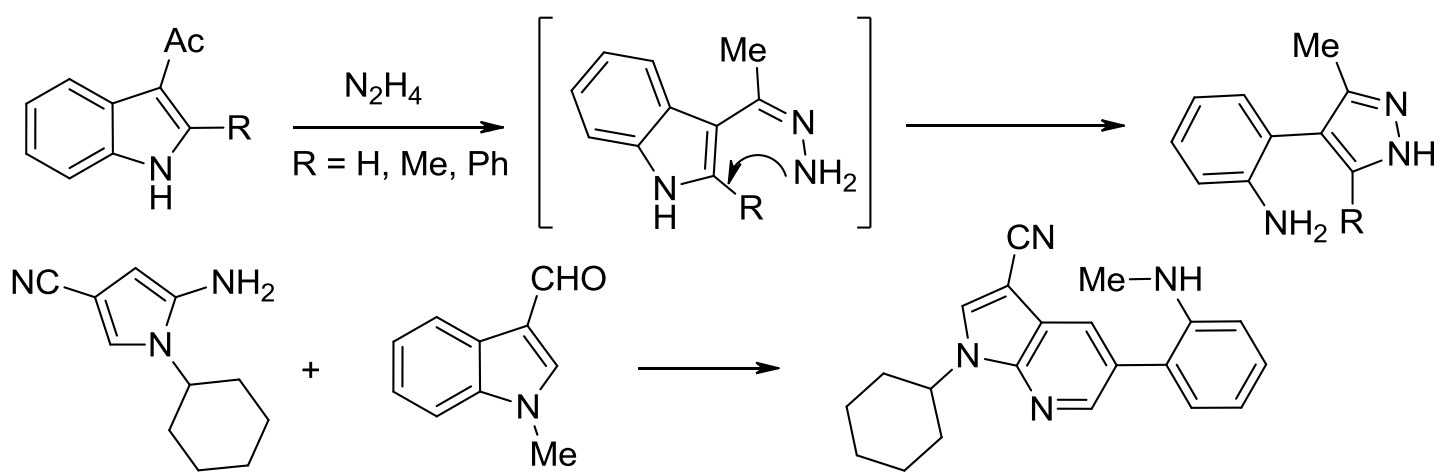

We found that the reaction of thioamide $\mathbf{1}$ with indole-3-carbaldehyde $\mathbf{2}$ in the presence of base, followed by the treatment of formed indole 4 with excessive $\mathrm{KOH}$ in boiling EtOH leads to the formation of a white precipitate, which we suggested to be potassium salt of 5-(2-aminophenyl)-2-thioxo-1,2dihydropyridin-3-carbonitrile 3 . The IR spectrum of salt 3 revealed the expected absorption bands corresponding to $\mathrm{NH}_{2}$ - and conjugated $\mathrm{N} \equiv \mathrm{C}$ groups, however, NMR spectra did not match the expected structure. The detailed analysis of spectral data allowed us to conclude that the product in fact is potassium 6-amino-3,5-dicyano-4-(1H-indol-3-yl)pyridine-2-thiolate 5 . The yield of thiolate 5 was $61 \%$. A possible mechanism for the formation of 5 includes retro-Knoevenagel reaction of compound 4 to give thioamide 1 ; the reaction of $\mathbf{1}$ with $\mathbf{4}$ afforded the Michael adduct $\mathbf{6}$ which undergo cyclization to give intermediate 1,4-dihydropyridine-2-thiolate $\mathbf{7}$ followed by in situ aromatization: 


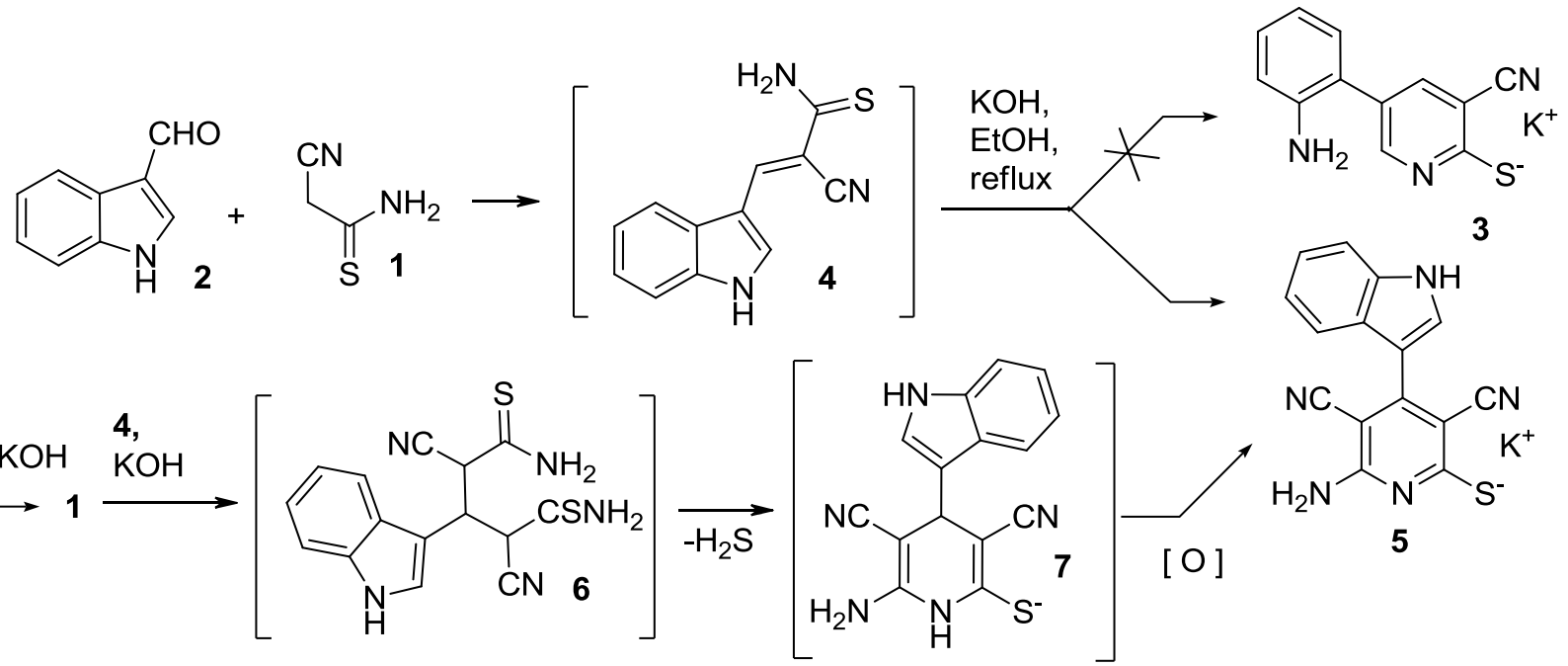

Upon treatment with acids and alkyl halides in basic media, thiolate $\mathbf{5}$ gave 2thioxopyridine $\mathbf{8}$ and 2-(alkylthio)pyridines $\mathbf{9}$ or thieno[2,3-b]pyridines $\mathbf{1 0}$, respectively:

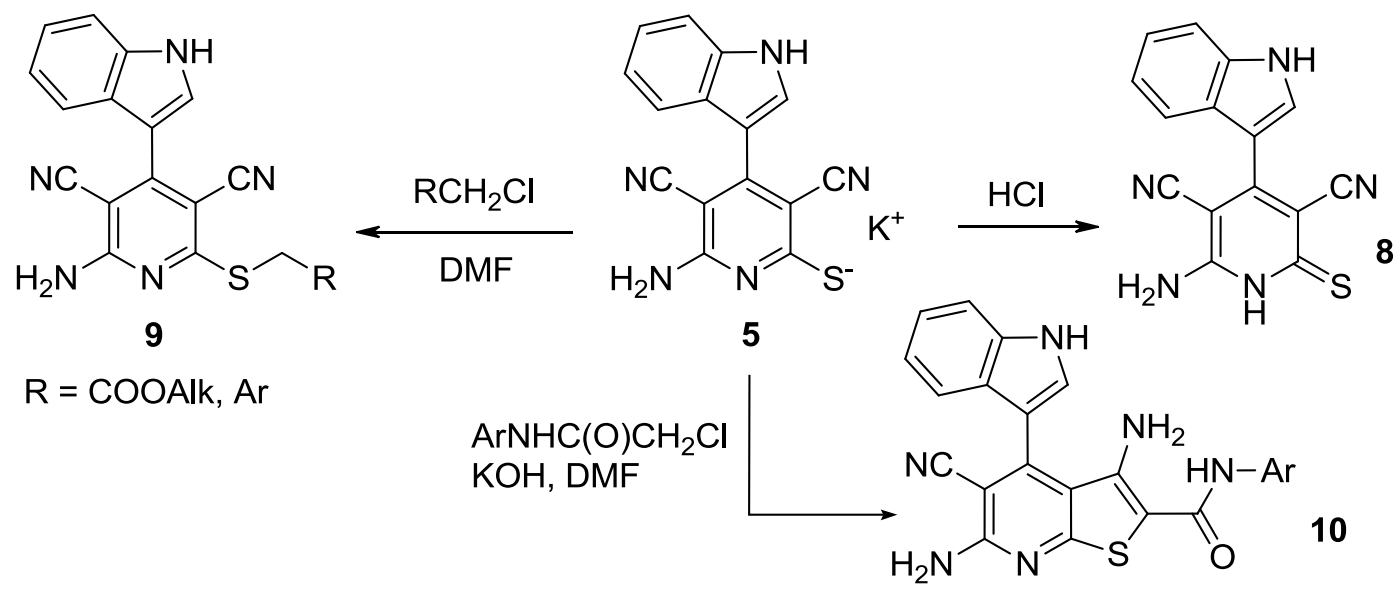

In summary, we failed to prepare any indole ring cleavage products in the reaction of cyanothioacetamide with indole-3-carbaldehyde. The product was recognized as potassium 6-amino-3,5-dicyano-4-(1H-indol-3-yl)pyridine-2thiolate. Though not being neither atom-economic nor preparative, the method we describe here demonstrates a new approach to the synthesis of 6amino-3,5-dicyanopyridine-2-thiolates and -thiones, which have been reported as bioactive molecules or their precursors. Full experimental details will be reported elsewhere.

\section{References}

1. Kolotaev A.V., Belen'kii L.I., Kononikhin A.S., Krayushkin M.M. // Russ. Chem. Bull. Int. Ed. 2006. Vol. 55. P. 892-897. DOI https://doi.org/10.1007/s11172-006-0348-2 
2. Vecchione M.K., Sun A.X., Seidel D. // Chem. Sci. 2011. Vol. 2. P. 21782181. DOI: $10.1039 / \mathrm{C} 1 \mathrm{SC} 00506 \mathrm{E}$

3. Lee S., Park S.B. // Org. Lett. 2009. Vol.11. P. 5214-5217. DOI: $10.1021 / \mathrm{ol} 902147 \mathrm{u}$

4. Lee S., Jo A., Park S.B. // Med. Chem. Commun. 2013. Vol. 4. P. 228-232. DOI: $10.1039 / \mathrm{c} 2 \mathrm{md} 20169 \mathrm{k}$

5. $\quad$ Knepper I., Iaroshenko V.O., Vilches-Herrera M., Domke L., Mkrtchyan S., Zahid M., Villinger A., Langer P. // Tetrahedron. 2011. Vol. 67. No. 29. P. 52935303. DOI https://doi.org/10.1016/j.tet.2011.05.037

6. Liu C., Zhou L., Jiang D., Gu Y. // Asian J. Org. Chem. 2016. Vol. 5. No. 3. P. 367-372. DOI 10.1002/ajoc.201500497

7. Vilches-Herrera M. Synthetic approaches for the synthesis of 7azaindole derivatives using 5-amino-1R-1H-pyrrole-3-carbonitrile as useful building block. Dissertation zur Erlangung des akademischen Grades doktor rerum naturalium (Dr. rer. nat.) der Mathematischder Naturwissenschaftlichen Fakultät der Universität Rostock. Rostock, 2012. P. 6. Avail. URL: http://rosdok.unirostock.de/file/rosdok_derivate_0000005017/Dissertation_VilchesHerrera_2013.pdf 